\title{
OPENING STATEMENT
}

\author{
By W. F. WeEks \\ (President, International Glaciological Society)
}

IT is a great pleasure to welcome you on behalf of the International Glaciological Society to the Symposium on Remote Sensing in Glaciology. The subject for the Symposium was selected by the Council of the Society and as a Council member at the time of this selection, $\mathrm{I}$, for one, think that we picked a winner. Our decision was made difficult by the fact that this symposium follows our Symposium on the Hydrology of Glaciers. We felt that this was rather "a hard act to follow" in that we believed that it had stimulated a significant amount of research on this subject by a number of widely separated investigators. In essence we believed that by organizing our meeting, we had caused a significant increase in our understanding of glacier hydrology.

Once we had convinced ourselves that we had accomplished this, the least we could do was to try to do it again. To do this, we were asking ourselves to accomplish a feat which is much closer to the art of a politician than to that of a scientist. By this I mean that we needed to have the ability to look at a crowd and instinctively know to the second which way they were going to change and why. Then one-half second before they changed, we could leap in front of them, raise our banner high and yell "Glaciers in the know think that remote sensing is much milder". Everyone would cheer and charge off in the correct direction to do what they were gcing to do before we appeared. However, now there is an important difference, because we can feel that we inspired them. Without our meeting it would never have happened! Perhaps this is true, but more likely it is only thinking that it is true that matters. In a way our task was even more difficult than the politicians because the time delays in organizing a meeting caused us to guess three years before the fact. During this three-year period, I have never doubted that we made the right decision.

I believe that the remote sensing of snow and ice is in an interesting transition period at the present time, changing from essentially qualitative, descriptive, remote sensing, carried on largely as "art for art's sake", to the quantitative collection of data by remote sensing for the purposes of both feeding and validating the current physical models that are being developed to describe the geophysical behaviour of glaciological entities. This is a fascinating time, in that the requirements of the models are continually posing problems to which the current answer is "we can't measure that", and, even if we could, with what confidence can we utilize our limited data to describe the vast expanses of snow and ice that we actually wish to describe? Also, how can we speedily reduce all this maze of data into a convenient numerical format so that it is useful before the fact? In many glaciological problems we will clearly need to use remote sensing to give a geophysical "diagnosis before the autopsy" and that is a tall order.

Ladies and gentlemen, I challenge you to look glaciological remote sensing squarely in the eye and charge! The Society is delighted that you are here and we urge you to debate the problems facing us during our meetings as well as in the evenings when you can enlist the support of a number of excellent English brews. Now let us do as the musicians say and "get it on". 